\title{
Vacaciones: derecho de los trabajadores contratados a tiempo parcial
}

Susana Silva Villacorta

\section{Introducción}

El trabajo constituye fuente de riqueza. Tal como lo establece nuestra Constitución, "es base del bienestar social y un medio de realización


mente a través del tiempo pues, por su propia naturaleza, el hombre está destinado y llamado al trabajo ${ }^{2}$.

Sin embargo, en lo accidental, van ocurriendo cambios, se sustituyen unos intereses por otros, aparecen nuevas necesidades y es preciso que las relaciones laborales se adapten a estas transformaciones. Es por ello que el nuevo marco laboral se caracteriza por una tendencia a la flexibilización, lo cual implica, entre otros, nuevas formas de distribución de las jornadas de trabajo.

Como bien señalaba Alonso Olea, lo que el trabajador debe no es tiempo de trabajo, sino "trabajo prestado durante un cierto tiempo". Pero, a criterio del legislador, la duración de la jornada constituye un elemento tipificante del contrato laboral.

En virtud de esto, el trabajo a tiempo parcial ha sido regulado como un trabajo marginal, presumiento que dichos contratos no constituyen medio de visa de quienes prestan los servicios, sino que simplemente son utilizados como complemento de actividades no lucrativas. Sin considerar que, principalmente, han sido los contratos a tiempo parcial

\footnotetext{
1 Artículo $22^{\circ}$ de la Constitución Política del Perú.

2 Cfr. M. Alonso Olea, Las Fuentes del Derecho. En especial del Derecho del Trabajo según la Constitución, $2^{\circ}$ ed., Madrid, Civitas, 1990, p. 30.
} 
los que han incorporado al mercado laboral a quienes requieren mayor protección (mujeres y jóvenes no calificados); que, actualmente es esta forma de contratación una de las medidas para combatir el grave problema de desempleo.-tratándose muchas veces de la única renta percibida-, y que además son el medio idóneo para satisfacer las nuevas necesidades de las empresas; los trabajadores a tiempo parcial han sido privados de casi todos los beneficios sociales percibidos por quienes trabajan en una jornada ordinaria, no obstante constituir una relación laboral común con una duración menor.

Dada la importancia del tema, y siendo imprescindible determinar si esta clase trabajadora tiene derecho a descanso vacacional -de acuerdo con el fundamento de dicho beneficio y según lo establecido por la legislación vigente- para evitar situaciones injustas; hemos querido contribuir a ello con esta investigación.

La escasez de la doctrina y jurisprudencia nacional sobre el tema nos ha animado, por el contrario, a continuar en el estudio, convencidos de que es necesario un análisis previo para que en la realidad no se vulneren los derechos otorgados a los trabajadores, en este caso, el derecho a vacaciones.

Esta investigación intenta demostrar que, el goce del descanso anual también corresponde a los trabajadores a tiempo parcial. Esta conformada por cuatro capítulos. En el primero se explica ciertas nociones generales sobre las vacaciones y el trabajo a tiempo parcial, aclarando que, de acuerdo al fundamento de aquéllas no se justifica su privación a estos trabajadores. En el segundo capítulo comentamos brevemente las normas que en Perú tratan el tema, a fin de determinar si ellas les reconocen el descanso vacacional. Asimismo, considerando que el Derecho del Trabajo español ha ejercido gran influencia en nuestras normas laborales, se recoge legislación y jurisprudencia española con el objetivo de comparar los criterios reguladores en uno y otro sistema. En el capítulo siguiente explicamos la obligatoriedad de las normas internacionales, ya que precisamente uno de los dispositivos que regulan el derecho a vacaciones, es un convenio internacional ratificado por el Perú. Por último, en el capítulo IV, se señala los criterios utilizados para solucionar un conflicto normativo, pues la situación se presenta en el ordenamiento jurídico nacional, en lo referente a descanso anual de los trabajadores a tiempo parcial. 
El Derecho laboral, tal como fue concebido, estaba basado en un sistema en el que los derechos de los trabajadores se iban incrementando y los cambios consistían en una mayor protección. Se dijo al respecto que se pensaba demasiado en amparar al trabajador y demasiado poco en la viabilidad económica de la empresa, que al fin y al cabo es su fuente de trabajo. Ese fue el comienzo de la flexibilización.

Pero, dejar en situación precaria a una clase trabajadora, sin otra justificación que la de incentivar a los empleadores a crear más puestos de trabajo mediante contratos a tiempo parcial, no significa combatir el desempleo, sino aumentar el subempleo, la explotación y la desigualdad. Es imposible que la violación de los derechos del hombre genere progreso; como afirma la OIT, sin justicia no habrá paz .

\section{Nociones generales}

\section{Vacaciones}

\subsection{Definición}

Las vacaciones, término proveniente del latín vacare (cesar) constituyen una suspensión de la prestación del trabajador amparada por la ley, proporcionándole a aquél un período de descanso anual remunerado.

La OIT ha señalado que "por vacación anual retribuida de los asalariados se entiende un número previamente determinado de jornadas consecutivas, fuera de los días festivos, días de enfermedad y convalescencia, durante los cuales, cada año, llenando el trabajador ciertas condiciones de servicio, interrumpe su trabajo y continúa percibiendo su remuneración" 4 .

Las vacaciones son definidas por la doctrina peruana en general como aquel derecho de los trabajadores, adquirido una vez cumplidos determinados requisitos, consiste en suspender la prestación de sus servicios durante cierto número de días del año, sin pérdida de la remuneración

3 Cfr. Preámbulo de la Constitución de la Organización Internacional del Trabajo, primer considerando (contrario senst).

4 A. Ruprecht, "Vacaciones", en Enciclopedia Jurídica Omeba, t. XXVI, Buenos Aires, Bibliográfica Omeba, 1981, p. 604. 
habitual, a fin de restaurar sus fuerzas y entregarse a sus ocupaciones personales o a la distracción ${ }^{5}$.

\subsection{Naturaleza jurídica}

Las vacaciones suponen un derecho a percibir el salario sin contraprestación laboral a cambio. La Ley de Productividad y Competitividad Laboral (D.S. $N^{\circ} 003-97-T R$ ) regula el descanso vacacional como una de las causas de suspensión del contrato de trabajo ${ }^{6}$. Asimismo, señala que tal suspensión puede ser de modo imperfecto cuando el empleador debe abonar remuneración sin contraprestación efectiva de labores ${ }^{7}$. Aquí se incluiría el descanso vacacional, de acuerdo a lo establecido por el artículo $16^{\circ}$ del D.S. $N^{\circ} 012-92-T R$ y el artículo $16^{\circ}$ del Dec. Leg. $\mathrm{N}^{\circ} 713^{8}$.

Ruprecht ${ }^{9}$ señala que se han formulado tres teorías respecto a su naturaleza jurídica:

a) Constituyen un premio al trabajador: surgen como liberalidad patronal, recayendo sobre el personal que el empleador considere eficiente.

Esta teoría no corresponde a la realidad pues las vacaciones se otorgan obligatoriamente, con independencia de que su beneficiario haya sido un buen o mal trabajador.

b) Carácter salarial: El descanso vacacional es una licencia como otras, un derecho que la ley otorga, con características propias pero no exclusivas, pues, por ejemplo, las enfermedades o accidentes de trabajo también son remunerados por el tiempo que marca la ley.

5 Cfr. AA.VV., "Derecho al Descanso Vacacional", Informativo Caballero Bustamante, $\mathrm{N}^{\circ} 371,1997$, p. D 1. y AA.VV., "Suspensión del Contrato de Trabajo", Asesoría Laboral, N ${ }^{\circ}$ 68,1996, p. 5.

6 Artículo $12^{\circ}$, inciso d.

7 Artículo $11^{\circ}$, segundo párrafo.

8 D.S. $\mathrm{N}^{\circ}$ 012-92-TR:

Artículo $16^{\circ}$ : "La remuneración vacaciones es equivalente a la que el trabajador hubiera percibido habitual y regularmente en caso de continuar laborando...".

Dec.Leg. $N^{\circ} 713$ :

Artículo $16^{\circ}$ : "La remuneración vacacional será abonada al trabajador antes del inicio del descanso".

9 Cfr. A. Ruprecht, op. cit., p. 604. 
c) Carácter asistencial: La colectividad en compensación del provecho que recibe con el trabajo de los operarios, satisface a éstos, indirectamente, el importe de las remuneraciones correspondientes al período de descanso anual, para que puedan gozar de ese beneficio.

Doctrina reciente sobre este tema entiende que: "De alguna forma el marcado acento histórico de las vacaciones como una concesión, premio o licencia pierde progresiva significación, situándose como un resultado "natural" ante el compromiso de la prestación laboral anual"10.

\subsection{Fundamento}

El descanso vacacional se fundamenta en la necesidad de que el trabajador disfrute de un período prudencial de holganza, a fin de restaurar las energías consumidas en el proceso productivo, lo cual no se logra plenamente con el descanso semanal.

El otorgamiento de vacaciones podría poner en peligro la salud física y síquica del trabajador. Además, no se trata sólo de reparar las energías del organismo; más que el reposo físico, su efecto estriba en la tranquilidad espiritual, porque sólo entonces el trabajador puede recuperarse de la fatiga del esfuerzo diario, también le proporciona la posibilidad de reencontrarse con su familia y consigo mismo al poder convivir todo el tiempo con los suyos y no solamente en las horas libres. Cabe agregar que en la actualidad es posible -dada la facilidad de los transportes y su bajo costo relativo- abandonar simultáneamente la rutina y los ambientes habituales, hoy urbanos, de la vida y de trabajo, logrando así un efectivo disfrute de este beneficio.

Actualmente, cierta doctrina incluso señala que las vacaciones anuales están perdiendo el carácter de ser un período de mera recuperación de fuerzas físicas o psíquicas (finalidad avalada en un contexto en que la prestación laboral era muy prolongada: jornadas de hasta 14 horas). En el presente la evaluación de esta institución se entiende como una respuesta a los cambios en el sistema organizativo y a las nuevas demandas de una sociedad dirigida a incrementar el tiempo libre y a realizar actividades recreativas, formativas que no tienen el carácter de

10 H. Merino Senovilla. El trabajo a tiempo parcial, Valladolid, Lex Nova, 1994, p. 317. 
productivas o laborales y que merecen protección. Se trata de salvaguardar la coincidencia de este tiempo de no trabajo con la familia y las actividades sociales ${ }^{11}$.

Es importante señalar que el descanso vacacional no redunda sólo a favor del trabajador sino también del propio empleador, esto justifica que el empleador remunere al trabajador sin que realice la labor debida. Esta remuneración constituiría la contraprestación por el trabajo que el operario, con renovadas fuerzas, realiza durante el resto del año ${ }^{12}$.

En general, razones de orden fisiológico, sicológico, social y familiar han llevado al establecimiento de este instituto, cuyo otorgamiento forma parte de un interés recíproco del patrón y del trabajador.

\section{Trabajo a tiempo parcial}

\subsection{Definición}

La OIT considera como trabajo a tiempo parcial a aquel trabajo efectuado regularmente durante una parte del día o de la semana sensiblemente inferior a la duración normal del trabajo por acuerdo voluntario entre el trabajador y empresario ${ }^{13}$.

Al hablar de trabajo a tiempo parcial se hace referencia a la prestación de servicios en una jornada de trabajo inferior a la ordinaria del centro de trabajo. Puede ser el trabajo en ciertas horas al día, de ciertos días de la semana, de ciertas semanas de mes o de algunos meses del año ${ }^{14}$. Sin embargo, la doctrina nacional entiende como contrato a tiempo parcial aquél que tiene una jornada de trabajo inferior a cuatro horas diarias en promedio, al dividir la jornada semanal entre el número de días trabajados; pues aunque en nuestro ordenamiento no existe

11 Cfr. M. Fernández López, "Retroactividad del convenio colectivo y cláusula penal en materia de vacaciones", Revista Política Social, No 144, 1984, p. 292, cit. por H. Merino Senovilla, op. cit., p. 317.

12 Cfr. A. Briceño Ruiz, Derecho individual del trabajo, México D. F. Marla, 1985, pp. 198-199.

13 Cfr. OIT, Informe VI de la 48 Conferencia Internacional de Trabajo, Ginebra, Oficina Internacional del Trabajo, 1963, pp. 96-97, cit. por A. Ojeda Aviles, "El contrato a tiempo parcial en España", Asesoría Laboral, $N^{\circ} 40,1994$, p. 19.

14 Cfr. AA.VV. "El tiempo como elemento de contrato del trabajo". Asesoría Laboral, $N^{\circ} 67,1996$, p. 5 
una definición expresa al respecto, eso se puede inferir de la legislación vigente $^{15}$.

\subsection{Origen y evolución}

El rol que ha desempeñado el trabajo a tiempo parcial ha experimentado profundos cambios. En un inicio fue concebido como una puerta de entrada al mercado de trabajo para sectores poco representativos en este ámbito, como las mujeres y los jóvenes antes de consolidar su situación profesional. Es decir, originalmente fue destinado para trabajadores de baja calificación, sin experiencia profesional y con un empleo marginal ${ }^{16}$.

Un segundo momento se presenta, sin abandonar la primera idea, al configurarse el trabajo a tiempo parcial como la vía idónea de adaptación del trabajo a los cambios, caracterizados éstos por las nuevas formas de organización del trabajo -debido al resurgimiento de la autonomía individual, en sustitución del intervencionismo estatal-, por la transformación de los procesos productivos -como resultado de las innovaciones tecnológicas-. Así como por las alteraciones en los bienes a producir -debido a las nuevas demandas de la población y a las nuevas exigencias empresariales-, justificándose las reformas en el reparto del tiempo del trabajo. De esta manera, el trabajo a tiempo parcial resultó ser el instrumento apropiado para el nuevo marco laboral que se presentaba, añadiéndole la ventaja para el empresario a un coste reduci$\mathrm{do}^{17}$.

Actualmente, esta forma de contratación sirve para paliar el problema del desempleo. En un mercado de trabajo con alta tasa de paro como el nuestro, los contratos de trabajo a tiempo parcial posibilitan un empleo a un mayor número de personas, constituyendo incluso

15 Principalmente de los siguientes artículos del D.S. No 001-96-TR (26/1/96):

Artículo $11^{\circ}$ : "Los trabajadores contratados a tiempo parcial tienen derecho a los beneficios laborales, siempre que para su percepción no se exija el cumplimiento del requisito mínimo de cuatro horas diarias de labor".

Artículo $12^{\circ}$ : "Se considera cumplido el requisito de cuatro horas en los casos en que la jornada semanal del trabajador dividida entre seis o cinco días, según corresponda, resulta en promedio no menor de cuatro horas diarias".

16 Cfr. H. Merino Senovilla, op.cit., p. 112.

17 Cfr. Ibidem. 
muchas veces su única renta. Asimismo se presentan situaciones de pluriempleo, acumulando varios contratos a tiempo parcial.

Sin embargo, la legislación no le otorga la protección necesaria, tratándolo como un trabajador marginal y no constitutivo de medio fundamental de vida. Las normas no han considerado que, ante la grave escasez de empleo, muchas veces estos trabajos no constituyen una opción voluntaria del trabajador, sino los ofertados o bien los disponibles.

\subsection{Régimen jurídico}

Si bien los contratos de trabajo a tiempo parcial no constituyen per se una modalidad de naturaleza temporal ${ }^{18}$, la ley les asigna un peculiar régimen jurídico, caracterizado por la eventualidad más absoluta. Su incorporación al texto normativo al menos supone la cobertura legal del cumplimiento de una jornada menor a la ordinaria, que es de cuatro o más horas. A través de estos contratos pueden realizarse tanto labores permanentes como temporales.

El ordenamiento laboral vigente contempla condiciones desiguales para el trabajador a tiempo parcial frente a quienes trabajan a tiempo completo. El contenido principal de la relación laboral a tiempo parcial -los derechos y obligaciones de estos trabajadores- se basa en el tiempo de trabajo, siendo este elemento el principal condicionante y determinante de la relación.

Según lo dispuesto por el artículo $11^{\circ}$ del reglamento del TUO de la LFE, los trabajadores contratados en una jornada de trabajo superior a cuatro horas tienen derecho a todos los beneficios sociales, mientras que los trabajadores contratados a tiempo parcial sólo gozan de aquellos beneficios que para su percepción no se exija el cumplimiento del requisito mínimo de cuatro horas diarias de labor. Al respecto la doctrina peruana ha entendido que los trabajadores, a tiempo parcial tendrían derecho a seguro de vida, seguridad social y gratificaciones, pero

18 Los contratos sujetos a modalidad deben ajustarse a lo dispuesto por el artículo $53^{\circ}$, D.S. $N^{\circ} 003-97-T R(27 / 03 / 97)$. En este tipo de contratos y en los contratos a tiempo parcial, el factor temporal incide sobre aspectos diferentes: en aquéllos se refiere a la duración del vínculo laboral, que puede ser a plazo fijo o indeterminado. En los contratos a tiempo parcial se refiere a la duración de la jornada, tema que será desarrollado en el siguiente punto. 
estarían privados de CTS, protección contra el despido arbitrario, utilidades y vacaciones ${ }^{19}$.

La Ley de Productividad y Competitividad Laboral (D.S.-003-97TR) establece en el artículo $4^{\circ}$, que puede celebrarse por escrito contratos en régimen de tiempo parcial sin limitación alguna; es decir, que las empresas podrán contratar los trabajadores a tiempo parcial que requieran.

Se trata, pues, de un contrato auténticamente precario. El legislador mantiene la secular situación de desamparo de quienes lo prestan y al mismo tiempo otorga una libertad irrestricta a los empleadores para contratar bajo esta forma. Con ello se posibilita el empleo desviado de contratos de trabajo a tiempo parcial, para cubrir en condiciones de total precariedad, puestos permanentes, contraviniendo principios jurídicos básicos e incluso normas constitucionales ${ }^{20}$.

\subsection{El tiempo como elemento del contrato de trabajo}

El que se prive de ciertos beneficios sociales a los trabajadores que presten servicios por menos de cuatro horas diarias se fundamenta en el no cumplir con el requisito de la jornada mínima, lo cual no altera la substancia de la relación laboral, pues los elementos esenciales del contrato de trabajo: prestación personal, subordinación y remuneración, están presentes.

La jornada de trabajo es el tiempo durante el cual -en forma diaria, semanal o mensual- el trabajador se encuentra a disposición de su empleador, con el fin de cumplir la prestación laboral que éste le exige.

La jornada de trabajo, sin ser elemento esencial del contrato de trabajo, va a tipificarlo.

El factor temporal se constituye en "medida de la prestación debida" ${ }^{21}$ y además es determinante el contenido del contrato. La obligación del trabajador, como obligación de prestar una actividad, sólo es posible que se concrete en una u otra cantidad. Es por ello que algunos afirman que el objeto de la relación laboral no es meramente el trabajo

19 Cfr. AA.VV., "El tiempo como ...", op. cit., p.7.

20 Cfr. capítulo IV.

21 Alarcón Caracuel. La ordenación del tiempo del trabajo, Madrid, Tecnos, 1988, p. 65. Citr. Pot H.Merino Senovilla, op. cit., p. 148. 
sino un determinado tiempo de trabajo, por lo que, la alteración del elemento tiempo supondría una prestación distinta ${ }^{22}$. Sin embargo, al respecto, Alonso Olea señala que lo que el trabajador debe no es tiempo de trabajo sino trabajo durante cierto tiempo ${ }^{23}$, fórmula aceptada mayoritariamente por la doctrina ya que, sin restarle importancia al factor temporal, reconoce que lo fundamental de la relación laboral es la actividad desarrollada por el trabajador en cumplimiento de su obligación, actividad que estará cuantificada.

El tiempo de trabajo en el trabajo a tiempo parcial es inferior siempre al trabajo a tiempo completo. Esto va a definir y configurar al trabajo a tiempo parcial entre el resto de modalidades contractuales y frente al contrato ordinario o habitual. Por consiguiente, el elemento temporal, en el trabajo a tiempo parcial, quedaría elevado como aspecto constitutivo de la prestación ${ }^{24}$, así lo habría considerado el legislador al otorgarle un tratamiento desigual a estos trabajadores.

Sin embargo, se puede afirmar que el trabajo a tiempo parcial carece de características sustanciales que le otorguen entidad propia y separada frente a la denominada relación laboral común o a tiempo completo, siendo la única diferencia entre ambas la menor duración de la jornada.

Por consiguiente, se podría concluir que la diversidad en la duración de la prestación no altera el negocio jurídico; en consecuencia, las diferencias con la relación común vienen establecidas no por la característica de la prestación, sino por una opción del legislador.

\section{Legislación: antecedentes y situación actual del derecho a vacacio- nes pagadas de los trabajadores a tiempo parcial}

La incorporación del derecho a descanso anual en la legislación positiva es bastante reciente en comparación con otros beneficios laborales. Al finalizar la primera década de este siglo se dictan las primeras leyes otorgando vacaciones y desde entonces este instituto ha adquirido un

22 Cfr. Merino Senovilla, M., op. cit., p. 151.

23 Cfr. M. Alonso Olea y M.E. Casas Baamonde, Derecho del trabajo, $12^{\circ}$ ed., Madrid, Universidad Complutense, 1991, p. 241.

24 Cfr. H. Merino Senovilla, op. cit., p. 152. 
gran desarrollo, casi todos los países lo han establecido, si bien difieren en cuanto a la forma de su concesión.

Tratándose la presente investigación del derecho al descanso anual de quienes trabajan a tiempo parcial, a continuación se señala las normas que se han dictado al respecto, a fin de determinar si ellos gozan o no de dicho beneficio.

\section{Derecho peruano}

El 15 de diciembre de 1959, mediante Res. Leg. N 13284, el Perú ratifica el Convenio Internacional de Trabajo $\mathrm{N}^{\circ} 52$ sobre vacaciones anuales pagadas, el cual reconoce a los trabajadores un descanso anual remunerado de seis días laborables, por lo menos, sin establecer excepciones por el número de horas que comprende la jornada.

\section{Convenio $\mathrm{N}^{\circ} 52$}

Convenio relativo a las vacaciones anuales pagada

(Aprobada por Resolución Legislativa $N^{\circ} 13284$, de 15/12/59)

La Conferencia General de la Organización Internacional del Trabajo:

Convocada en Ginebra por el Consejo de Administración de la Oficina Internacional de Trabajo, y congregada en dicha ciudad el 04 de junio de 1936 en su vigésima reunión:

Después de haber decidido adoptar diversas proposiciones relativas a las vacaciones anuales pagadas, cuestión que constituye el segundo punto del orden del día de la reunión, y

Después de haber decidido que dichas proposiciones revistan la forma de un convenio internacional, adopta con fecha veinticuatro de junio de mil novecientos treinta y seis, el siguiente Convenio que podrá ser citado como el Convenio sobre las vacaciones pagadas, 1936:

\section{Artículo $1^{\circ}$}

1. El presente convenio se aplica a todas las personas empleadas en las empresas o establecimientos siguientes, ya sean éstos públicos o privados. 
a) empresas en las cuales se manufacturen, modifiquen, limpien, reparen, adornen, terminen, preparen para la venta, destruyan o demuelan productos, o en las cuales las materias sufran una transformación, incluidas las empresas de construcción de buques, y la producción, transformación y transmisión de electricidad o cualquier clase de fuerza motriz:

b) empresas que se dediquen exclusiva o principalmente a trabajos de construcción, reconstrucción, conservación, reparación, modificación o demolición de las obras siguientes:

- edificios

- ferrocarriles,

- tranvías.

- aeropuertos,

- puertos,

- muelles,

- obras de protección contra la acción de los ríos y el mar,

- canales,

- instalaciones para la navegación interior, marítima o área,

- caminos,

- túneles,

- puentes,

- viaductos,

- cloacas colectoras,

- cloacas ordinarias,

- pozos,

- instalaciones para riegos y drenajes,

- instalaciones de telecomunicación,

- instalaciones para la producción o distribución de fuerza eléctrica y de gas,

- oleoductos,

- instalaciones para la distribución del agua, y las empresas dedicadas a otros trabajos similares a las obras de preparación a los trabajos antes mencionados;

c) empresas dedicadas al transporte de viajeros o mercancías por carretera, ferrocarril o vía de agua interior, o área comprendida la manipulación de mercancías en los muelles, embarcaciones, almacenes y aeropuertos.

d) minas, canteras e industrias extractivas de cualquier clase; 
e) establecimientos comerciales, comprendidos los servicios de correos y de telecomunicaciones;

f) establecimientos y administraciones en los que las personas empleadas efectúen esencialmente trabajos de oficina.

g) empresas de periódicos;

h) establecimientos dedicados al tratamiento u hospitalización de enfermos, lisiados, indigentes o alienados.

i) hoteles, restaurantes, pensiones, cafés y otros establecimientos análogos;

j) teatros y otros lugares públicos de diversión;

k) establecimientos que revistan un carácter a la vez comercial e industrial y que no corresponden totalmente a una de las categorías precedentes.

2. La autoridad competente de cada país, previa consulta a las principales organizaciones interesadas de empleadores y de trabajadores cuando dichas organizaciones existan, deberá determinar la línea de demarcación entre las empresas y establecimientos antes mencionados y los que no están incluidos en el presente Convenio.

3. La autoridad competente de cada país podrá exceptuar de la aplicación del presente Convenio a:

a) las personas empleadas en empresas o establecimientos donde solamente estén ocupados los miembros de la familia del empleador;

b) las personas empleadas en la administración pública, cuyas condiciones de trabajo les concedan derecho a vacaciones de una duración, por lo menos, igual a la prevista por el presente Convenio.

Artículo $2^{\circ}$

1. Toda persona a la que se aplique el presente convenio tendrá derecho, después de un año de servicio continuo, a unas vacaciones anuales pagadas de seis días laborales, por lo menos. 2. Las personas menores de dieciséis años, incluidos los aprendices, tendrán derecho, después de un año de servicio continuo 
a vacaciones pagadas de doce días laborables, por lo menos.

3. No se computan a los efectos de vacaciones anuales pagadas:

a) los días feriados oficiales o establecidos por la costumbre:

b) la interrupciones en la asistencia al trabajo debidas a enfermedad.

4. La legislación nacional podrá autorizar, a título excepcional, el fraccionamiento de la parte de las vacaciones anuales que exceda de la duración mínima prevista por el presente artículo. 5. La duración de las vacaciones anuales pagadas deberá aumentar progresivamente con la duración del servicio, en la forma que determine la legislación nacional.

Artículo $4^{\circ}$

Se considera nulo todo acuerdo que implique el abandono del derecho a vacaciones anuales pagadas o la renuncia a las mismas.

Artículo $8^{\circ}$

Todo miembro que aplique el presente Convenio deberá establecer un sistema de sanciones que garantice su aplicación.

La Constitución de 1933, vigente al ratificarse este convenio, no recogía sin embargo, el derecho a vacaciones; omisión que fue subsanada por la Constitución de 1979. Esta Constitución estableció en el artículo 44 -ubicado en el título I: De los derechos y deberes fundamentales de la persona- que: “... Los trabajadores tienen derecho a descanso semanal remunerado, vacaciones anuales pagadas y compensación por tiempo de servicios...".

De este modo, el derecho a vacaciones es reconocido como derecho fundamental de los trabajadores, sin distinción.

El 8 de noviembre de 1991 se dicta el Dec. Leg. N 713 sobre descansos remunerados. El capítulo III regula las vacaciones anuales: 


\section{Capítulo III}

De las vacaciones anuales

Artículo $10^{\circ}$.- El trabajador tiene derecho a treinta días calendario de descanso. Dicho derecho está condicionado, además, al cumplimiento del récord que se señala a continuación.

a) Tratándose de trabajadores cuya jornada ordinaria es de seis días a la semana, haber realizado labor efectiva por lo menos doscientos sesenta días en dicho período.

b) Tratándose de trabajadores cuya jornada ordinaria es de cinco días a la semana, haber realizado labor efectiva por lo menos de doscientas diez días en dicho período.

c) En los casos en que el plan de trabajo se desarrolle en sólo cuatro o tres días a la semana sufra paralizaciones temporales autorizadas por la Autoridad Administrativa de Trabajo, los trabajadores tendrán derecho al goce vacacional, siempre que sus faltas injustificadas no excedan de diez en dicho período. Se consideran faltas injustificadas las ausencias no comprobables para el récord conforme al artículo $13^{\circ}$ de esta ley.

Artículo $12^{\circ}$.- Para efectos de récord vacacional se considera como días efectivos de trabajo los siguientes.

a) La jornada ordinaria mínima de cuatro horas.

Al exigir la jornada mínima de 4 horas para gozar del descanso vacacional, pareciera que la norma contraviene su propio espíritu expresado en su considerando:

...Que resulta necesario armonizar, consolidar, sin discriminación ${ }^{25}$, la legislación sobre descansos remunerados de los trabajadores sujetos al régimen laboral de la actividad privada, propendiendo a la modernización de sus normas y adecuándolas para convertirlas en instrumentos que alientan la productividad y con ello el desarrollo nacional... 
Posteriormente se expide el reglamento del Dec. Leg. $\mathrm{N}^{\circ} 713$ mediante D.S. No 012-92-TR del 2 de diciembre de 1992, el cual establece en el artículo 11: "Tienen derecho a descanso vacacional el trabajador que cumpla una jornada ordinaria mínima de cuatro (04) horas, siempre que haya cumplido dentro del año de servicios, el récord previsto en el artículo $10^{\circ}$ del Decreto Legislativo".

Contrario sensu esta norma niega el derecho a vacaciones de quienes trabajan menos de cuatro horas.

El 26 de abril de 1993, mediante D.S. N 004-93-TR se aprobó el reglamento de la LFE, el cual se refiere expresamente a los trabajadores a tiempo parcial.

Título II

Del contrato de trabajo

Capítulo I

De las Normas Generales

Artículo $6^{\circ}$.- Los trabajadores que sean contratados a tiempo parcial, tienen acceso a todos los derechos y beneficios legales en que no exija para su percepción el requisito de las cuatro (4) horas diarias...

La presente disposición no es de aplicación, en los casos en que a la Ley o la convención colectiva exija el cumplimiento de un mínimo de horas para tener derecho a determinados beneficios laborales, salvo lo dispuesto en el artículo siguiente:

Artículo $7^{\circ}$.- En aplicación del convenio $N^{\circ} 52$ de la Organización Internacional de Trabajo, sobre vacaciones pagadas, ratificado por el Perú, en virtud de la Resolución Legislativa $N^{\circ} 13284$ de 15 de diciembre de 1959, los trabajadores que laboren menos de (4) horas diarias tendrán derecho a descanso anual pagado, siempre y cuando cumplan con el récord correspondiente.

Sin embargo, aunque este dispositivo legal reconocía la vigencia del convenio $\mathrm{N}^{\circ} 52$ y por tanto, el derecho a vacaciones de los trabajadores a tiempo parcial, su redacción originaba confusiones al exigir el cum- 
plimiento del récord correspondiente (artículo 7 , in fine). Según el artículo $12^{\circ}$ del Dec. Leg. $N^{\circ} 713$, para cumplir el récord vacacional es necesaria la jornada ordinaria mínima de cuatro horas, con lo cual sería imposible aplicar la norma en cuestión. Para que este dispositivo no sea un absurdo, se estaría refiriendo únicamente al récord señalado en el artículo $10^{\circ}$ del Decreto Legislativo $\mathrm{N}^{\circ} 713$, sin tomar en cuenta el artículo $12^{\circ}$; lo cual, aunque dota de sentido al artículo 7 del reglamento de la LFE, no resulta convincente. Al respecto, la interpretación de la doctrina no es unívoca ${ }^{26}$.

El 24 de enero de 1996 se dicta el reglamento del TUO de la LFE mediante D.S. $N^{\circ}$ 001-96-TR, el cual no contiene mención alguna al derecho vacacional de los trabajadores contratados a tiempo parcial, $\mathrm{Al}$ respecto la doctrina reaccionó favorablemente ${ }^{27}$.

Su texto ya no recoge lo establecido por el artículo 7 del anterior reglamento. El artículo $11^{\circ}$ deroga tácitamente, dicho dispositivo al establecer que: "Los trabajadores contratados a tiempo parcial tienen derecho a los beneficios laborales, siempre que para su percepción no se exija el cumplimiento del requisito mínimo de cuatro (4) horas diarias de labor".

En la Carta Magna vigente se reitera la jerarquía constitucional del derecho a vacaciones anuales pagadas, aunque ha variado su ubicación: no se encuentra en el capítulo que regula los derechos fundamentales de la persona, sino en el capítulo correspondiente a los derechos sociales y económicos, que recoge el derecho al trabajo.

26 La revista Asesoría Laboral, en un informe especial señala que para efecros de record vacacional se considera como día efectivo de trabajo, entre otros, la jornada ordinaria mínima de cuatro horas; pero que para los trabajadores a tiempo parcial e tomaría en cuenta su jornada ordinaria que es inferior a cuatro horas - Cfr. AA.VV., "Descansos Remunerados", Asesoría Laboral, $\mathrm{N}^{\circ} 32,1993$, p. 6

En otro número se señala, por el contrario, que cumplir con el record correspondiente establecido por el artículo $7^{\circ}$ del D.S. No $004-93-T R$ no era posible porque para cumplirlo se exige una jornada mínima de cuatro horas, agregando que, dicho error, ha sido corregido en el nuevo reglamento (D.S. No 001-96-TR) - Cfr. AA.VV., "Descansos Remunerados", Asesoría Laboral, $\mathrm{N}^{\circ} 62,1996$, p. 7

27 En la revista Informe Laboral se sostiene que el nuevo reglamento contiene saludables rectificaciones respecto al anterior, pues no hace referencia al derecho a descanso anual de quienes trabajan a tiempo parcial, lo cual -consideran- estaba impropiamente regulado en el reglamento anterior, quedando su regulación al Dec. Leg. $\mathrm{N}^{\circ} 713$, sus normas complementarias y a los Convenios de la OIT suscritas por nuestro país - Cfr. AA.VV., "Reglamento de la Ley de Fomento del Empleo: Rectificaciones saludables", Informe Laboral, $\mathrm{N}^{\circ} 124, \mathrm{~V}$. XI, 1996 , p. 3 
Asimismo, con respecto a la Constitución anterior, la redacción del artículo en cuestión ha sido modificada. El artículo $25^{\circ}$ de la Constitución vigente establece: “... Los trabajadores tienen derecho a descanso semanal y anual remunerados. Su disfrute y compensación se regulan por ley o por convenio".

Corresponde a la ley o al convenio el desarrollo de este derecho. El término convenio hace referencia a la convención colectiva ya que los convenios internacionales se encuentran en la actual Constitución bajo la denominación tratado ${ }^{28}$.

Independientemente de las variaciones señaladas, el reconocimiento del derecho al descanso anual por la Constitución lo dota de intangibilidad por normas infraconstitucionales. Cabe añadir, que al igual que la Constitución anterior, este derecho es otorgado a los trabajadores en general, sin establecer excepciones.

En resumen, en cuanto a las normas vigentes que regulan el derecho a vacaciones se podría decir que la Constitución y el Convenio 52 reconocen este derecho de los trabajadores sin distinciones en razón de su jornada. En contraposición el Dec. Leg. 713 y su reglamento establecen como requisitos un mínimo de 4 horas de jornada ordinaria para poder gozar de 30 días de descanso anual y según el reglamento de la LFE, los trabajadores a tiempo parcial estarían privados de este derecho por no cumplir con el requisito señalado.

Ante esta situación la doctrina peruana que trata el tema afirma mayoritariamente que los trabajadores a tiempo parcial carecen del derecho a vacaciones, sustentando su posición únicamente en lo establecido por determinadas normas del conjunto de la legislación vigente aplicable en este caso, sin percibir, que en realidad, existe un conflicto de normas ${ }^{29}$.

\section{Derecho comparado: España}

La ley laboral peruana ha recibido un gran influjo de la legislación española sobre Derecho del trabajo. Es por ello que se realizará un

28 Cfr. Capítulo IV, 1.2.

29 Cfr. AA.VV.,. "El tiempo como..." op. cit., pp. 7-8 y AA.VV., "Derecho al Descanso..." op. cit., p.1. 
escueto comentario sobre las normas que regulan el trabajo a tiempo parcial y el derecho a vacaciones en dicho país.

El contrato a tiempo parcial en España se encuentra regulado por el artículo 12 del ET (Ley $\mathrm{N}^{\circ}$ 8/1980), siendo su redacción actual la siguiente:

Artículo $12^{\circ}$ : Contrato a tiempo parcial y contrato de relevo.

1. El trabajador se entenderá contratado a tiempo parcial cuando preste servicios durante un número de horas al día, a la semana, al mes o al año, inferior al considerado como habitual en la actividad que se trate en dichos periodos de tiempo.

2. El contrato a tiempo parcial podrá concertarse a tiempo indefinido o por duración determinada en los supuestos que legalmente se permita la utilización de esta modalidad de contratación, excepto en el contrato de aprendizaje.

Asimismo, el RD 2317-1993 del 29 de diciembre, incluye en su texto, dispositivos sobre el contrato a tiempo parcial. El artículo $19^{\circ}$ establece: "Los trabajadores a tiempo parcial tendrán los mismos derechos que los trabajadores a tiempo completo, salvo las peculiaridades que, en función del tiempo trabajado, estén establecidos por ley o puedan determinarse por la negociación colectiva”.

Es decir, la regulación de los derechos y obligaciones de los trabajadores a tiempo parcial responde a los principios de equiparación y proporcionalidad con respecto a los trabajadores a tiempo completo.

Los diferentes dispositivos que han normado la relación laboral a tiempo parcial presentan algunas diferencias entre ellas, sin embargo, el denominador común en la regulación de los derechos derivados de esta relación ha sido la observancia del principio de igualdad.

La norma que anteriormente regulaba el contrato a tiempo parcial era el RD 1991/1984, el cual establecía como criterio general la equiparación al disponer en el artículo $2^{\circ}$, inciso 1: "Los trabajadores contratados a tiempo parcial tendrán los derechos que la ley o los convenios colectivos reconozcan a los trabajadores a tiempo completo...".

Según la doctrina española, en esta norma se incluye tanto la proporcionalidad en el disfrute de determinados derechos como la paridad 
de otros en que debe aplicarse íntegramente al no estar conectados con lo específico de esta relación ${ }^{30}$.

El articulo $19^{\circ}$ del RD 2317/1993, vigente actualmente, establece una fórmula más general, acorde con el objetivo de la flexibilidad. Aún así, el principio de equiparación y de proporcionalidad no ha sido alterado ya que el elemento diferenciador -sobre el que incide este dispositivo- es el tiempo trabajado, es decir, el trabajo ya realizado, determinado por el tiempo. En aplicación de la regla de proporcionalidad. Sólo podrán establecerse ciertos matices sobre aquellos derechos relacionados con el elemento temporal, tipificante de este contrato. El resto de condiciones laborales no podrán fijar peculiaridades si no existe conexión con la duración del trabajo ${ }^{31}$.

Al respecto, el Tribunal Constitucional español califica como irrazonable las diferencias de trato que "se implantan atendiendo sólo y exclusivamente al menor número de horas trabajadas, porque, tomándose sólo en cuenta este factor diferencial, se ignora el menor poder contractual de estos trabajadores atípicos" ${ }^{\prime 2}$.

En cuanto al derecho a descanso anual retribuído, éste se encuentra regulado por el Convenio $\mathrm{N}^{\circ} 132$ de la OIT ${ }^{33}$, ratificado por España el 16 de junio de 1972 y aplicable a los trabajadores asalariados con exclusión de la "gente de mar"; por el convenio $N^{\circ} 101$ de la OIT ${ }^{34}$, ratificado por España el 8 de abril de 1971 y aplicable a los trabajadores agrícolas; y por el artículo $38 \mathrm{ET}$ que tal como señala Montoya Melgar, es "aplicable a todos ${ }^{35}$ los trabajadores por cuenta ajena y dependientes" ${ }^{36}$. Esta norma en el primer inciso establece como período mínimo el de 30 días naturales, que el contrato o convenio colectivo sólo pueden mejorar: "El período de vacaciones anuales retribuidas no sustituible por compensación económica, será el pactado en convenio colectivo o contrato individual. En ningún caso ${ }^{37}$ la duración será inferior a treinta días naturales...".

30 Cfr. H. Merino Senovilla, op. cit., p. 306.

31 Cfr. Ibid., p. 307.

32 S. $22 / 1994$ de 27 de enero, fundamento 4 , apartado c) cit. por H. Merino Senovilla, op. cit. p. 307.

33 No ha sido ratificado por el Perú.

34 Ratificado por el Perú mediante Res. Leg. 13284 del 15/12/59.

35 Énfasis añadido.

36 A. Montoya Melgar, Derecho del Trabajo, $13^{\circ}$,ed. Madrid, Tecnos, 1992, p.352.

37 Énfasis añadido. 
La redacción del artículo $38^{\circ} \mathrm{ET}$ es categórica, el derecho a vacaciones se otorga de modo general, no dando lugar a especulaciones sobre si dicho derecho está referido a un contrato a tiempo completo o a tiempo parcial.

Interpretando este dispositivo en concordancia en el artículo $19^{\circ}$ del RD 2317/1993 es posible afirmar que en España, los trabajadores a tiempo parcial gozan de derecho a descanso anual al igual que los trabajadores a tiempo completo, ya que ni la normatividad específica ni la general prevén diferencias para el disfrute del período de vacaciones entre unos trabajadores y otros ${ }^{38}$. El criterio de la proporcionalidad se aplica no para fijar el número de días que componen el descanso anual -treinta para ambos casos-; sino para determinar la retribución que recibirán en este período, la cual será fijada en relación a la jornada mensual que el trabajador a tiempo parcial viene realizando, de modo que, como retribución vacacional recibirá el salario mensual que normalmente percibe ${ }^{39}$.

\section{Normas internacionales laborales}

Al tratar la legislación nacional sobre el derecho a descanso anual de los trabajadores a tiempo parcial se señaló que el Perú había ratificado el Convenio 52 de la OIT sobre vacaciones anuales pagadas en $1959^{40}$. En el presente capítulo se intentará explicar la relevancia jurídica que tiene este hecho.

\section{La voluntad interestatal como fuente de normas}

Las normas internacionales nacen de la misma voluntad de los Estados que en ellas convienen. Mediante ellas se aspira a una homogeneidad normativa por encima de los límites nacionales.

38 Parece que el elemento que influye en el devengo del descanso anual es la duración de la relación laboral, y no la prestación (jornada diaria, semanal, mensual, etc.); de modo que si la actividad se desarrolla a lo largo del año natural, el derecho a descanso es completo, por el contrario, si la actividad se ve interrumpida -por ejemplo en los contratos temporales de duración inferior a un año- la correspondencia de este derecho será proporcional al tiempo de duración de la relación. Este es el critrerio utilizado por la jurisprudencia española. Cfr. H. Senovilla, op. cit., pp. 318-319.

39 Crf. Ibid., pp. 320-322.

40 Cfr. Capítulo II, 1. 
Lo que llevó a regular las relaciones laborales a escala internacional fue la consideración de que en realidad se trata de un problema que afecta al hombre mismo, al trabajador -cuya protección no puede depender exclusivamente del sistema jurídico que su país adopte-, asi como razones de índole económico ${ }^{41}$.Es así como en 1919 se constituyó la OIT para promover la elaboración y establecimiento de una legislación social en todos sus Estados miembros.

El conjunto de normas internacionales del trabajo son el resultado de una vasta y particular "negociación colectiva": trabajadores, empresarios y gobiernos que representan a la casi totalidad de los países del mundo, deciden y negocian, en pie de igualdad, temas de trascendencia social. Logrado el consenso sobre los fines perseguidos, el acuerdo se plasma en un texto internacional con naturaleza normativa ${ }^{42}$.

Pero jurídicamente, el Estado continúa siendo soberano y de su voluntad, en definitiva, depende la aplicación o no de dichas normas. En la voluntad última del Estado que ratifica un convenio reside la posibilidad de que sus dispositivos se incorporen a su ordenamiento jurídico ${ }^{43}$.

\section{Convenios de la OIT}

\subsection{Definición}

Es el acuerdo de voluntades emanado de la Conferencia Internacional de la OIT que se adoptan esperando convertirse en Derecho nacional o interno mediante su ratificación por los Estados miembros.

\subsection{Naturaleza jurídica}

Existen dos corrientes doctrinales al respecto: una les atribuye carácter de ley; la otra, de contrato ${ }^{44}$.

41 El coste económico de las mejoras en las condiciones de rrabajo hubieran colocado en posición desventajosa al país que las llevara a cabo frente a aquéllos que no lo hicieran.

42 Cfr. I. Barbero Marcos, Normas Internacionales del Trabajo de la OIT, T.I, Valladolid, Lex Nova, 1993. P. 13.

43 Cfr. M. Alonso García, Curso de Derecho del Trabajo, $2^{\circ}$ ed., Barcelona Ariel, 1967 , pp. $87-88$.

44 Cfr. G. Von Potobsky y H. Bartolomei de la Cruz, La Organización Internacional del Trabajo, Buenos Aires, Astrea, 1990, p. 26. 
Scelle, que sostiene la primera tesis, señala que los convenios son verdaderas leyes internacionales dictadas por un organismo legislativo del mismo carácter. En ese sentido Plá Rodríguez distingue entre la adopción de un convenio por la conferencia, que constituye el actoregla; y la ratificación por un Estado obligándose a él, es el acto-condición. Es decir la ratificación implica la adhesión del Estado a un acto legislativo preexistente.

Mahaim, Ramadier y otros defienden la teoría de los tratados-contratos, resaltando el acuerdo de voluntades necesario para la existencia de un convenio y su ratificación para darle un carácter ejecutorio. En otras palabras, la Conferencia Internacional del Trabajo sólo elabora proyectos de convenios, cuyo valor legislativo depende exclusivamente de las ratificaciones.

Es importante destacar que ambas tesis insisten en el elemento básico de la ratificación de los convenios; solo así los derechos y obligaciones establecidos por tales normas surgirán en el orden interno de un Estado.

\subsection{Obligatoriedad de los convenios}

La OIT no constituye un ente supranacional cuyas normas tengan un carácter imperativo directo. Para su obligatoriedad, los convenios requieren la ratificación del país respectivo ${ }^{45}$.

\subsubsection{Ratificación}

Es el acto formal de un Estado en virtud del cual decide aceptar las proposiciones contenidas en un convenio. Es el cumplimiento de la condición requerida para que el convenio pueda devenir eficaz; una vea ratificado es fuente de obligaciones.

\subsubsection{Obligaciones emanadas de la ratificación}

La ratificación de un convenio acarrea dos obligaciones básicas para el

45 Sin embargo, la falta de ratificación de un convenio por un Estado miembro no lo exime del acatamiento de los principios que lo inspiran, en la medida en que están expresados en la Constitución de la OIT. Cfr. Ibid., p. 31. 
país interesado: proceder a su aplicación y someterse a los procedimientos destinados a verificarla. Es decir, los Estados ratificantes se comprometen a armonizar su legislación y su práctica nacional con las disposiciones del convenio, aceptando también la sumisión a una supervisión internacional.

\section{A. Aplicación de los convenios}

El artículo $19^{\circ}$, párrafo 5 , d, de la constitución de la OIT prevé expresamente que el Estado que ratifica un convenio se compromete a adoptar "las medidas necesarias para hacer efectivas las disposiciones de dicho convenio". Esta obligación implica adecuar la normativa nacional existente al marco que desarrolla el convenio ratificado, así como desarrollar legislativamente la norma internacional sin contravenir sus dispositivos $^{46}$.

Pero no consiste únicamente en dar efectividad al convenio en la legislación, sino también en asegurar su aplicación en la práctica, de tal modo que las cláusulas del convenio no sean letra muerta.

En este sentido, la Convención de Viena señala en sus artículos $26^{\circ}$ y $27^{\circ}$, respectivamente, que: "Todo Tratado en vigor obliga a las partes y debe ser cumplido por ellas de buena fe" y "una parte no podrá invocar las disposiciones de su derecho interno como justificación del incumplimiento de un tratado...".

Aunque esta convención no ha sido ratificada por el Perú, la doctrina reconoce que ha unificado la costumbre internacional sobre esta materia ${ }^{47}$.Al respecto Verdross afirma: "Ningún Estado puede sustraerse a una obligación jurídica-internacional invocando su derecho interno. Esto vale incluso para las leyes constitucionales opuestas al Derecho Internacional" 48 .

Cabe destacar que la característica fundamental de los convenios internacionales es la de constituir norma mínima, es decir, el derecho interno puede evolucionar por encima de lo que ellos estipulan. Así lo

46 Cfr. M. Cannessa Montejo, "Los convenios de la O.I.T. y la nueva Constitución peruana", Asesoría Laboral, $N^{\circ} 37,1994$, p. 9.

47 Cfr. Ibid., p. 10.

48 A. Verdross, Derecho Internacional Público, Madrid, Aguilar Ediciones, 1982, p. 66, cit. por M. Canessa Montejo, op. cit., p. 11. 
expresa la Constitución de la OIT en su artículo $19^{\circ}$ párrafo 8 , al disponer: "En ningún caso ... la ratificación de un convenio por cualquier miembro, menoscabará cualquier ley, sentencia, costumbre o acuerdo que garantice a los trabajadores condiciones más favorables que los que figuren en el convenio...".

\section{B. Mecanismos de control}

Otra de las obligaciones que origina la ratificación es la de someterse a los mecanismos de control para verificar que el convenio se está aplicando efectivamente. Este control está ejercido por la OIT, los Estados miembros que hubieran ratificado también el convenio y las organizaciones profesionales de los empresarios y de trabajadores del propio país.

La OIT fiscaliza si los Estados están dando cumplimiento a los convenios ratificados mediante las Memorias que aquéllos deben presentar a la Oficina Internacional del Trabajo, acerca de las medidas adoptadas para poner en ejecución los convenios. Así lo dispone el artículo $22^{\circ}$ de la Constitución de la OIT.

Los estados miembros que hubieran ratificado el convenio podrán formular quejas contra otro Estado que, a su parecer no haya dado cumplimiento satisfactorio a un convenio ratificado por ambos. En este caso, el Consejo de Administración puede intervenir nombrando una comisión que deberá redactar un informe sobre los hechos determinantes del litigio o formulando recomendaciones sobre las medidas a adoptar, puede incluso llegar a intervenir nombrando una comisión que deberá redactar un informe sobre los hechos determinantes del litigio o formulando recomendaciones sobre las medidas a adoptar, puede incluso llegar a intervenir el Tribunal Internacional de Justicia. Este procedimiento está regulado por la Constitución de la OIT, en los artículos 26 y siguientes.

Las organizaciones profesionales de empresarios o de trabajadores pueden formular reclamaciones ante la Oficina Internacional del Trabajo alegando que su país no ha adoptado las medidas necesarias para el cumplimiento satisfactorio del convenio ratificado, según lo establecen los artículos 24 y 25 de la Constitución de la OIT. En este supuesto, el Consejo de Administración comunica el reclamo al gobierno contra el cual se ha presentado. Si el Consejo no considera satisfactoria la 
respuesta recibida de parte del gobierno -o si no hay respuesta algunapodrá hacer pública el reclamo.

Por consiguiente el control que se ejerce sobre los Estados ratificantes, se trata, en realidad de una condena moral más que de una medida jurídica. No hay mejor control en cuanto a la aplicación y cumplimiento de un convenio ratificado que el que presten los mismos Estados.

\section{El Perú y el cumplimiento del convenio 52 de la OIT}

Como se señaló anteriormente, el Perú ratificó el Convenio 52 de la OIT, el cual reconoce el derecho a vacaciones anuales pagadas de seis días laborables, por lo menos, a todas las personas comprendidas en su artículo $1^{\circ}$, sin establecer excepciones en virtud de la duración de la jornada ${ }^{49}$.

Asimismo, se ha hecho referencia al deber de los Estados de presentar una memoria anual ante la Oficina Internacional del Trabajo para verificar el cumplimiento de los convenios ${ }^{50}$. Pues bien, la memoria correspondiente a la aplicación del Convenio 52 deberá ser presentada en $1998^{51}$, siendo necesario -según lo establecido por el Consejo de Administración- proporcionar información sobre leyes, reglamentos y demás normas que regulen las vacaciones anuales pagadas, información detallada respecto de cada uno de los artículos del convenio sobre leyes, reglamentos, disposiciones judiciales, administrativas $\mathrm{u}$ otras medidas que lo aplican, etc. ${ }^{52}$.

La legislación laboral interna, vigente en la actualidad, que regula los descansos remunerados, está constituida por el Dec. Leg. $\mathrm{N}^{\circ} 713$ y su reglamento (DS $\mathrm{N}^{\circ}$ 012-92-TR), que según lo establecido en los artículos ya citados ${ }^{53}$, negarían el derecho a vacaciones anuales pagadas a quienes trabajan a tiempo parcial. En consecuencia, el Perú, a través de tales normas, estaría contraviniendo el Convenio 52 que ha ratificado, estaría incumpliendo las obligaciones internacionales que ha contraído y deberá dar cuenta de ello este año.

49 Cfr. P. 14.

50 Cfr. Capítulo III, 2.3.2., B.

51 OIT, Manual sobre procedimientos con materia de convenios y recomendaciones del trabajo, Ginebra, Oficina Internacional del Trabajo, 1984, p.16.

52 Cfr. Ibid., pp. 17-18. 
Cabe señalar que nuestra Constitución, en el artículo 118, inciso $1^{\circ}$ establece: "Corresponde al Presidente de la República: 1. Cumplir y hacer cumplir la Constitución y los tratados, leyes y demás dispositivos legales", por lo que se podría afirmar que hay un incumplimiento de la propia norma constitucional.

\section{Solución al conflicto de normas}

Al finalizar la primera parte del capítulo II se señaló la existencia de un conflicto entre las normas vigentes que regulan el derecho a vacaciones, problemática que la doctrina peruana no se ha planteado pues mayoritariamente afirma que los trabajadores a tiempo parcial no gozan de tal beneficio.

El conflicto se produce cuando dos o más normas regulan el mismo hecho de modo incompatible entre sí. Ante esta situación es recomendable seleccionar sólo una de ellas para aplicarla al caso concreto.

Los criterios de selección son lo siguientes:

\section{Jerarquía de normas}

\subsection{Primacía de la Constitución}

"El orden jurídico -escribe Kelsen- no es un sistema de normas coordinadas entre sí, que se hallasen, por así decirlo, una al lado de la otra, en un mismo nivel; sino que se trata de una verdadera jerarquía de diferentes niveles de normas. La unidad de éstas hállase constituida por el hecho de que la creación de una norma -la de grado más bajo- se encuentra determinada por otra -de grado superior-, cuya creación es determinada, a su vez, por otra todavía más alta" ${ }^{\text {"54 }}$.

La doctrina kelnesiana sobre la jerarquía de las normas -situando a la Constitución en la cúspide de la célebre pirámide-, ha sido también

53 Cfr. pp. 16-17.

54 E. Chirinos Soto, La Nueva Constitución al alcance de todos, $3^{\circ}$ ed., Lima, AFA, 1984 , p. 1020 . 
recogido por nuestra Carta Magna en el artículo $51^{\circ}$, que establece: "La Constitución prevalece sobre toda norma legal; sobre las normas de inferior jerarquía, y así sucesivamente...".

Es por ello, que la consagración de normas, principios o derechos laborales a nivel constitucional supone una alta valorización del Derecho del Trabajo y de los intereses y bienes por él tutelados, significa que el orden jurídico nacional le reconoce máxima importancia. "Desde el punto de vista estrictamente técnico jurídico, el reconocimiento constitucional de un derecho supone más: crea una suerte de privilegio del bien jurídico tutelado o del valor consagrado, que lo vuelve intangible por normas infraconstitucionales..." 55 .

La Constitución de 1993, en el artículo $23^{\circ}$, reconoce el derecho a descanso anual remunerado de los trabajadores. Al respecto, Rondón Vásquez, afirma: "La expresión trabajadores comprende, sin excepción, a todas las personas que trabajan, cualesquiera que sean la naturaleza de su actividad y la duración del trabajo por día, semana o mes, entendiéndose que se puede establecer requisitos" 56 .

Nos adherimos plenamente a lo expresado por este autor, pues tal artículo, conforme está redactado, no está destinado sólo a determinadas categorías de trabajadores sino que el derecho se otorga de modo global. Al remitirnos a la ley o al convenio señala que ellos regularán su disfrute y compensación. Suponer que, en aplicación de esto último, la ley puede privar de dicho beneficio a ciertos trabajadores, sería irrazonable y arbitrario. Se vulneraría, el principio Non licet distinguere ubi lex non distinguit, y en consecuencia infringiría la propia Constitución, que no sólo ha reconocido el derecho de modo general, sino que, además establece expresamente que: "Ninguna relación laboral puede limitar el ejercicio de los derechos constitucionales..." 57 .

\subsection{Rango de los convenios en el ordenamiento jurídico peruano.}

La actual Constitución elimina el término convenio para referirse a los convenios internacionales, unificando bajo la denominación de trata-

55 G. Giugni, Diritto sindicale, $9^{\circ}$ ed., Bari, 1991, p. 271, cir por J. Ermida Uriarte, "Constitucionalización del Derecho Laboral", Asesoría Laboral, No26, 1993, p.19.

56 J. Rondón Vásquez, Derecho del Trabajo Individual, Lima Edial, 1995, p. 240.

57 Arrículo $23^{\circ}$, tercer párrafo. 
do a todas las normas internacionales sujetas a ser incorporadas dentro del ordenamiento jurídico nacional ${ }^{58}$.

El artículo $2^{\circ}$, numeral 1 de la Convención de Viena de 1969 establece en su inciso a) que: "se entiende por "tratado" un acuerdo internacional celebrado por escrito entre Estados y regido por el derecho internacional, ... cualquiera que sea su denominación particular".

El Perú -aunque no haya ratificado dicha convención- al unificar los términos en su texto constitucional, se adecúa a los criterios manejados en la doctrina internacional, en donde han desaparecido los distingos entre las normas internacionales por considerar que su denominación no tiene ninguna importancia desde el punto de vista del valor internacional de las obligaciones contraída ${ }^{59}$. Así

“... Cualquiera sea la denominación que se le de al instrumento, si se trata de un acuerdo de voluntades entre sujetos de derecho internacional destinado a producir efectos jurídicos regidos por el Derecho Internacional, es un tratado. Las diferentes denominaciones se explican por razones técnico-formales, pero no afectan su naturaleza jurídica ni implican una exclusión del concepto de tratado" ${ }^{\prime \prime}$.

Quedando aclarado que tratado y convenio son equivalentes, es posible hacer referencia al rango que ocupan en nuestro ordenamiento.

El Art. $55^{\circ}$ de la Constitución vigente establece: "Los tratados celebrados por el Estado y en vigor forman parte del derecho nacional". Este dispositivo recoge al igual que en la Constitución anterior el principio de recepción automática de las normas internacionales, pero no reconoce la prevalencia de la norma internacional frente a la ley interna en caso de conflicto como lo dispuso el artículo $101^{\circ}$ de la Constitución de 1979; tampoco menciona el rango normativo de que gozan los tratados en el ordenamiento nacional.

Sin embargo el artículo $200^{\circ}$ inciso 4 del título V "De las garantías constitucionales" es el que define el rango de los tratados internaciona-

58 Cfr. M. Canessa Montejo, op. cit., p.8.

59 Cfr. M. De la Lama Eggestedt, "Tratados en la Constitución" en F. Eguiguren Praeli, (ed.), Constitución política de 1979 y sus problemas de aplicación: 11 estudios interpretativos, Lima, Cultural Cuzco, 1987, p. 473.

60 Ibidem. 
les al establecer que: "Son garantías constitucionales: 4. La acción de inconstitucionalidad, que procede contra las normas que tienen rango de ley: leyes, ... tratados...". Con dicho dispositivo la Constitución de 1993 atribuye a los tratados internacionales rango de ley.

Si un tratado regula el mismo hecho que una ley interna de modo incompatible, en virtud del criterio de jerarquía no se podría establecer distingos jurídicos entre ambas, ya que gozan del mismo rango.

Sin embargo, es importante resaltar que en este caso se trata de un convenio internacional que recoge un derecho reconocido también por la propia Constitución. Al respecto, la cuarta disposición final y transitoria de la constitución señala:

"Las normas relativas a los derechos y a las libertades que la Constitución reconoce se interpretan de conformidad con la Declaración Universal de Derechos Humanos ${ }^{61}$ y con los tratados y acuerdos internacionales sobre las mismas materias ratificadas por el Perú".

De este modo, para establecer el sentido de un precepto constitucional, que reconoce un derecho también regulado por la Declaración Universal de Derechos Humanos y por un tratado, es indispensable acudir a estas normas internacionales. Surge así una vinculación intensa entre la Constitución y el tratado. Según Neves Mujica, esta situación equivale a una constitucionalización de dichos tratados:

“...Será posible, por tanto, interponer una acción de inconstitucionalidad contra una ley que transgreda la regulación de un derecho consagrado simultáneamente por la Constitución y un tratado ratificado, por una infracción de aspectos no contenidos en la primera (pues el artículo $25^{\circ}$ señala los trabajado-

61 La Declaración Universal de los Derechos Humanos aprobado por el Perú mediante Res. Leg. No 13282 el 9 de diciembre de 1959, establece:

Artículo 24: "Toda persona tiene derecho al descanso, al disfrute de tiempo libre, a una limitación razonable de la duración del trabajo y a vacaciones periódicas pagadas".

Artículo 30: "Nada en la presente Declaración podrá interpretarse en el sentido de que confiere derecho alguno al Estado, a un grupo o a una persona, para emprender y desarrollar actividades o realizar actos tendientes a la supresión de cualquiera de los derechos y libertades proclamadas en esta Declaración". 
res, de modo general) pero si en el segundo (ya que el artículo $2^{\circ}$ del convenio 52 otorga el descanso anual a toda persona a la que se aplique el convenio)"62.

En cuanto a la acción de inconstitucionalidad que aquí se señala, la norma que la desarrolla es la Ley $\mathrm{N}^{\circ} 26435$ (del $1^{\circ}$ de enero de 1995), que en su artículo $26^{\circ}$ dispone que tal acción se interpone contra la norma infractora dentro del plazo de seis meses, contados a partir de su publicación; vencido el plazo indicado, prescribe la acción, sin perjuicio de lo establecido por el artículo $51^{\circ}$ y por el segundo párrafo del artículo $138^{\circ}$ de la Constitución. Por consiguiente, al haberse vencido el plazo, ya no se podría interponer una acción de inconstitucionalidad contra el Dec. Leg. $\mathrm{N}^{\circ} 713$, el cual niega el derecho a treinta días de descanso vacacional a quienes tienen una jornada ordinaria menos de cuatro horas, que como ya se ha explicado infringe el artículo $25^{\circ}$ de la Constitución. Sin embargo, mediante una forzada interpretación podría entenderse que el Dec. Leg. $N^{\circ} 713$ no priva del derecho a vacaciones a los trabajadores a tiempo parcial, sino que simplemente a éstos no se les va a otorgar treinta días de vacaciones. Esta interpretación pierde sustento al leer el artículo 11 de su reglamento que expresamente señala: "Tiene derecho a descanso vacacional el trabajador que cumpla con una jornada ordinaria mínima, de cuatro (04) horas...".

Entablar una acción popular contra tal reglamento (DS $\mathrm{N}^{\circ} 012-92-$ TR), fundamentada en su infracción a la Constitución y al Convenio 52 , es igualmente imposible pues el artículo $6^{\circ}$ de la ley $N^{\circ} 24968$ (Ley Procesal de la Acción Popular) señala que cuando se trata de normas violatorias de la Constitución el plazo de prescripción es de cinco años a partir de la fecha de publicación, es decir, hasta el pasado diciembre $^{63}$.

En consecuencia, debido a la imposibilidad de entablar las referidas acciones, los jueces, en aplicación de los artículos 51 y $138^{64}$ de la Carta Magna, harán prevalecer la Constitución, interpretando su artí-

62 J. Neves Mujica, Introducción al Derecho del Trabajo, Lima, ARA, 1997, p. 71

63 El D:S. N ${ }^{\circ} 012-92-T R$ se publicó el 2 de diciembre de 1992.

64 Artículo 138.- "... En todo proceso, de existir incompatibilidad entre una norma constitucional y una norma legal, los jueces prefieren la primera. Igualmente, prefieren la norma legal sobre todo otra norma de rango inferior". 
culo $25^{\circ}$ de conformidad con el convenio 52 de la OIT y la Declaración Universal de los Derechos Humanos, según lo dispuesto por la cuarta disposición final y transitoria. En consecuencia se le reconocería el derecho a vacaciones a los trabajadores a tiempo parcial.

\section{Principio lex posterior derogar priori}

Otra solución para una concurrencia conflictiva entre un convenio de la OIT y una ley nacional es recurrir a este principio en razón de que ambas normas gozan del mismo rango jerárquico, es decir la norma posterior derogaría a la anterior independientemente de que sea nacional o internacional el dispositivo derogado.

Evidentemente este principio no es aplicable en ese sentido. Además de lo señalado en el punto anterior, la norma internacional no puede ser derogada por una norma interna dictada posteriormente ya que la denuncia de los convenios de la OIT es el único recurso que permite inaplicar las normas internacionales del trabajo ratificadas por un Estado.

\section{Principio de norma más favorable}

El Derecho del trabajo ha formulado un principio específico para la solución de los conflictos: cuando dos normas regulen incompatiblemente el mismo hecho, debe seleccionarse la que conceda más ventajas para el trabajador o clase trabajadora.

Sin embargo, este principio no ha sido recogido por nuestra Constitución. Al respecto la doctrina entiende que la recepción de los principios por el ordenamiento no es indispensable para su vigencia, ya que son meta-legales y su propia naturaleza los sitúa por encima del derecho positivo ${ }^{65}$. Además, la Ley Procesal de Trabajo ${ }^{66}$ en su artículo II establece expresamente la aplicación de la norma más favorable al trabajador. Es decir, la recepción de este principio por nuestro ordenamiento no tiene nivel constitucional pero sí legislativo.

Una vez reconocido que el convenio de la OIT y la ley interna son normas laborales y que asimismo ambas cumplen con los tres límites

65 Cfr. Neves Mujica, "Los principios del Derecho del Trabajo en la Constitución y el proyecto", Asesoría laboral, $N^{\circ} 31,1993$, p. 20.

66 Ley $\mathrm{N}^{\circ} 26636$ del 24/06/96. 
exigidos: materiales, instrumentales y aplicativos ${ }^{67}$ entonces, es posible la aplicación de este principio. Este es el caso del Convenio 52 de la OIT y del Dec. Leg. 713 (conjuntamente con su reglamento).

Como se señaló anteriormente, el tratado no puede dejarse sin efecto por la ley sino previa denuncia. Si esto no se ha dado debe preferirse aquél, mas aún si establece condiciones más favorables para una clase trabajadora. La norma peyorativa queda postergada en la aplicación pero no eliminada, sigue formando parte del ordenamiento ${ }^{68}$.

Esta solución corresponde a la naturaleza del Derecho laboral, protector del trabajador.

Por consiguiente, en el caso de quienes laboran en una jornada mayor a cuatro horas, la norma aplicable será el Dec. Leg. 713 y su reglamento, que otorga 30 días de descanso vacacional -en aplicación también dispuesta en el artículo $19^{\circ}$ inciso 8 de la Constitución de la OIT, que establece el carácter de norma mínima de los convenios- mientras que para los trabajadores a tiempo parcial la norma vigente más favorable es el convenio 52 de la OIT, que le reconoce por lo menos seis días de descanso anual.

\section{Otros principios}

En este punto se tratará sobre aquellos principios que en realidad no son propiamente utilizados para la solución de conflictos normativos, pero que de una u otra manera guardan relación con el tema investigado.

\subsection{Principio de condición más beneficiosa}

Se aplica en caso de sucesión de normas. Por tanto no existen normas concurrentes e incompatibles, sino que se trata de la eliminación de una primera regulación por otra siguiente que la sustituye.

En dicha sucesión de normas han sido disminuidos o ya no se contemplan los beneficios que los trabajadores venían disfrutando. "No se está ante un problema de comparación de normas, sino ante una comparación de condiciones laborales de las que el trabajador viniera bene-

67 J. Neves Mujica, op. cit., pp. 136-144.

68 Cfr. A. Montoya Melgar, op. cit., p. 216. 
ficiándose y las que se derivarían de la aplicación de una normativa sobrevenida que no contemplara aquellos beneficios" ${ }^{69}$. En virtud de este principio, aún con la nueva normativa, los trabajadores tienen derecho a retener tales beneficios. Es decir se plantea la ultraactividad de la norma bajo la cual nació el derecho.

Este principio se aplicaría a la sucesión de los reglamentos de la $\mathrm{LFE}^{70}$, pues en el anterior -aunque con dificultad para hacerlo viablese reconocía el derecho a vacaciones de los trabajadores a tiempo parcial, y en el que se encuentra vigente, dicho beneficio ya no se contem$\mathrm{pla}^{71}$. Ambas normas tienen el mismo origen, ámbito, rango. Por lo tanto la aplicación de tal principio sería posible ${ }^{72}$.

Sin embargo, la doctrina discrepa de la solución a este caso según el ordenamiento jurídico acoja la teoría de los derechos adquiridos o de los hechos cumplidos. Al respecto se discutía cuál era la posición de nuestro sistema-

La tercera disposición complementaria, transitoria y derogatoria del D.S: $N^{\circ}$ 003-97-TR ha venido a aclarar este punto estableciendo que a efecto de lo dispuesto en el artículo 62 de la Constitución ${ }^{73}$ la ley laboral sustituye a la anterior, salvo que haya sido incorporada al contrato de trabajo por pacto expreso.

Por tanto, en razón de esta disposición, no procedería aplicar el principio de condición más beneficiosa, por lo menos en el ámbito laboral ${ }^{74}$.

\subsection{Principio de igualdad}

Se trata en realidad, de un derecho recogido de nuestra Constitución ${ }^{75}$, que resultaría vulnerado si se privara del derecho a descanso anual a una clase trabajadora sin más caracteres diferentes que una jornada reducida.

69 Ibid, p. 220.

70 D.S. $\mathrm{N}^{\circ} 004-93-\mathrm{TR}$ y D.S. $\mathrm{N}^{\circ} 001-96-\mathrm{TR}$.

71 Cfr. pp. 16-17.

72 Cfr. J. Neves Mujica, op. cit., p. 147.

73 Artículo $62^{\circ}$ - "La libertad de contratar garantiza que las partes puedan pactar válidamente según las normas vigentes al tiempo del contrato. Los términos contractuales no pueden ser modificados por leyes y orras disposiciones de cualquier clase...".

74 Sin embargo, aún podría discutirse el que una norma reglamentaria esté desarrollando una norma constirucional en un sentido, al parecer contrario. 
El principio de igualdad, al estar reconocido expresamente por la Carta Maga -incluso, como uno de los derechos fundamentales de la persona-, vincula a los poderes públicos y gobierna el resto de fuentes normativas en razón del orden jerárquico del sistema de fuentes; así como por la naturaleza de las normas laborales, inspiradas para proteger al trabajador.

En la dualidad del tratamientos es donde se considera que radica la posible infracción al principio de igualdad ante la ley, al producir una discriminación para los trabajadores con una jornada inferior a cuatro horas, a los que se niega determinados beneficios sociales, frente a quienes superen dicha duración. Sobre qué trabajadores deben ser sujetos del derecho de vacaciones anuales retribuidas, compartimos la opinión de Demarás, el cual sostiene:

"Anhelamos el amparo general sin el privilegio de ciertas categorías de trabajadores; es decir, que todos se encuentren bajo las mismas disposiciones de legislación social que les beneficie, al margen de todo núcleo aristocrático dentro de la masa asalariada" 76 .

El desarrollo del principio de igualdad no conlleva la identidad de condiciones ni de derechos en sentido estricto. Se debe entender que caben diferenciaciones siempre que existan factores que justifiquen la desigualdad ${ }^{77}$. En este sentido, la peculiaridad de la menor duración de la jornada no puede empeorar o dejar en condiciones de inferioridad a los trabajadores. De dicha diferencia, sólo se puede extraer, en todo caso, la proporcionalidad del trato.

El principio de proporcionalidad se ha formulado en el marco del Estado de Derecho y en la esfera de los derechos constitucionales, como el criterio corrector que tiene la función de valorar las diferencias de

75 Constitución Política del Perú:

Artículo $2^{\circ}$ : "Toda persona tiene derecho: 2 A la igualdad ante la ley. Nadie debe ser discriminado por motivo de origen, raza, sexo, idioma, religión, opinión, condición económica o de cualquier otra índole".

76 Demarás, Tiempo libre de los trabajadores, Buenos Aires, 1942, p. 84, op. cit. G. Cabanellas, Tratado de Derecho Laboral, t. II, Buenos Aires, El Gráfico, 1949.

77 Cfr. Rodríguez Piñeiro y Fernández López, Igualdad y discriminación, Madrid, Tecnos, 1986, p. 53, cit. por M. Merino Senovilla, op. cit., p. 304. 
trato dispuestas por los poderes públicos ${ }^{78}$. Mediante este criterio se busca proteger de modo adecuado los derechos que se podrían ver menoscabados en razón de la presencia de ciertas desigualdades. "No toda diferencia o cualquier naturaleza en la diferencia produce cualquier desigualdad, sino que únicamente el trato diferente debe dispensarse en relación proporcional y racional de las características desiguales"79.

Por consiguiente, en respeto al principio de igualdad, los trabajadores a tiempo parcial gozarían también del descanso vacacional en razón de que este contrato carece de elementos que lleguen a alterar sustancialmente la relación laboral ${ }^{80}$. Las diferencias, derivadas de la reducción de la prestación, se regularán mediante el criterio de la proporcionalidad.

Este criterio, tal como ocurre en España, se aplicaría para determinar la remuneración a la que el trabajador tiene derecho durante el descanso anual, frente a la que, por dicho concepto, reciben los trabajadores a tiempo completo. En ese sentido, quienes laboran en una jornada inferior a las cuatro horas obtendrían la remuneración que normalmente perciben en un mes de acuerdo a las horas trabajadas en ese período, cuyo monto sería menor a lo percibido por quienes realizan la misma labor a tiempo completo. Pero tal criterio no se aplicaría para fijar el número de días que comprende el descanso vacacional de los trabajadores a tiempo parcial, pues tratándose de relaciones laborales esencialmente iguales, corresponde paridad de trato; tal como sostiene la jurisprudencia española: "Si la actividad se desarrolla o se va a desarrollar a lo largo del año natural, el derecho o descanso es completo..." $"$.

Por lo expuesto, y de acuerdo a lo establecido por el artículo $2^{\circ}$, inciso 2 de la Constitución de 1993, en concordancia con el artículo $25^{\circ}$-el cual, al referirse a la jornada legal establece un máximo de ocho horas, pero no un mínimo, otorgando el derecho a vacaciones a los

78 Cfr. Pedraz Penalva y Ortega Benito. "El principio de proporcionalidad y su configuración en la jurisprudencia del Tribunal Constitucional y Literatura especializada alemanas", Revista Poder Judicial, No 17, 1990, p. 69, cit. por H. Merino Senovilla, op. cit., p. 122.

79 M. Merino Senovilla, op. cit., p. 122.

80 Cfr. capítulo I, 2.4 .

81 Cfr. nota al pie de página $\mathrm{N}^{\circ} 38$. 
trabajadores en general sin señalar una duración mínima de su jornada-, los trabajadores a tiempo parcial gozarían también del derecho a treinta días de descanso anual.

Por tanto, el Dec. Leg. 713 y su reglamento estarian contraviniendo la Constitución en cuanto vulneran el principio de igualdad ante la ley. Dichas normas ni siquiera contemplan el criterio de la proporcionalidad para otorgar el derecho a vacaciones a los trabajadores a tiempo parcial -criterio que, como se ha explicado, no sería aplicable para establecer diferencias en cuanto al número de días de descanso- sino que, de plano, los privan de tal beneficio. Lo que se toma, entonces, es la norma constitucional en virtud de su superioridad jerárquica.

\section{Conclusiones}

Primera:

Se puede afirmar que en el trabajo a tiempo parcial no existen elementos especiales que justifiquen un régimen jurídico distinto. La única diferencia que presenta, frente a la relación común, es la menor duración de su jornada. La naturaleza jurídica del contrato y de la obligación laboral no varía por razón del tiempo: El trabajador continúa obligado a prestar sus servicios de modo personal y subordinado a favor del empleador, a cambio de una remuneración y durante la jornada acordada en el contrato, el cual puede ser celebrado sin necesidad de que concurran circunstancias determinadas.

Por todo ello el trabajo a tiempo parcial se debe tipificar como contrato laboral común en el que la duración de la jornada es menor a la ordinaria. En consecuencia, a los trabajadores a tiempo parcial les corresponde el mismo tratamiento jurídico que a quienes laboran a tiempo completo, es decir, tienen derechos y obligaciones equivalentes.

Segunda:

Atendiendo a la motivación y naturaleza del descanso vacacional, no habría razón alguna para excluir a los trabajadores a tiempo parcial del goce de tal beneficio. El derecho a descanso anual se fundamenta en razones de origen fisiológico, sociológico, social y familiar; $y$, aunque la jornada en el contrato a tiempo parcial sea menor, la obligación de trabajar ha sido cumplida en los términos acordados. Por tanto, tam- 
bién es indispensable un descanso mas aún teniendo en cuenta que actualmente, debido a la escasez de empleo y al alto costo de vida, muchas personas trabajan a tiempo parcial para distintos empleadores durante el día. De aquí que el derecho a vacaciones sea una consecuencia lógica derivada del vínculo laboral, por una prestación de servicios durante un año.

\section{Tercera:}

Los Estados están obligados a cumplir las obligaciones internacionales contraídas. El hecho vinculante es la ratificación de los tratados.

El Perú ha ratificado el Convenio 52 de la OIT y, por tanto, es su deber hacerlo efectivo y no transgredir sus normas, quedando sometido al control internacional.

\section{Cuarta:}

Actualmente existe un conflicto entre las normas que regulan el derecho a vacaciones: La Constitución y el Convenio 52 de la OIT reconocen este derecho a los trabajadores en general, sin distinciones en razón de su jornada. En contraposición, el Dec. Leg. $\mathrm{N}^{\circ} 713$ y su reglamento exigen el requisito de cuatro horas de jornada ordinaria como mínimo, para poder gozar de 30 días de descanso anual.

\section{Quinta:}

Los jueces, en virtud del criterio de jerarquía normativa, deben reconocer el derecho a descanso anual de los trabajadores a tiempo parcial; pues el artículo $25^{\circ}$ de la Constitución, -que recoge tal beneficio sin discriminación alguna- se interpreta de conformidad con el Convenio 52 de la OIT y la Declaración Universal de Derechos Humanos, según lo establecido por la propia Carta Magna (cuarta disposición final y transitoria).

\section{Sexta:}

Por otra parte, de acuerdo al principio de la norma más favorable principio propio del Derecho Laboral- los trabajadores a tiempo parcial gozan, por lo menos, de seis días de descanso anual, según lo establecido por el Convenio 52 de la OIT, que en su caso, es la norma a aplicar, frente al Dec. Leg. $\mathrm{N}^{\circ} 713$ que los priva de tal beneficio. 
Séptima:

En aplicación de las normas constitucionales, contenidas en el artículo $2^{\circ}$, inciso 2 , que recoge el principio de igualdad ante la ley; en concordancia con el artículo $25^{\circ}$, que reconoce el derecho a vacaciones de los trabajadores en general; y el artículo 23 que establece que ninguna relación laboral puede limitar el ejercicio de los derechos constitucionales, se concluye que corresponde a los trabajadores a tiempo parcial gozar de treinta días de descanso vacacional.

Es necesario considerar que la igualdad ante la ley, reconocida por la Constitución como un derecho fundamental, no implica necesariamente una identidad de condiciones; pues también se manifiesta a través del criterio de proporcionalidad, cuya función es adecuar la igualdad a situaciones desiguales. Sin embargo, tratándose de relaciones laborales equivalentes, en las cuales los elementos esenciales del contrato de trabajo (prestación personal, subordinación y remuneración) están igualmente presentes, el criterio de proporcionalidad sería aplicable sólo para determinar la remuneración a la que el trabajador a tiempo parcial tendría derecho durante el descanso anual, que sería menor a lo percibido por quienes realizan la misma labor a tiempo completo. Por tal razón del Dec. Leg. №713 y su reglamento infringen la Constitución misma al vulnerar un derecho consagrado por ella.

\section{Octava:}

Es evidente que, para adaptarse a las nuevas exigencias del mercado de trabajo, se requiere una normativa flexible que regule las relaciones laborales; la cual no debe ser entendida como una desregularización o, peor aún, un atropello- de los derechos de los trabajadores. Por ello considero necesario la promulgación de una norma clara, en la que expresamente se reconozca el derecho a descanso anual de 30 días que poseen quienes trabajan a tiempo parcial, para evitar se cometan injusticias al aplicar el De. Leg. $\mathrm{N}^{\circ} 713$ directamente, sin percatarse del conflicto de normas existente. Sólo así el Derecho del trabajo cumpliría con su razón de ser: la protección del trabajador. 


\section{Abreviaturas utilizadas}

D.S. Decreto Supremo

Dec. Leg. Decreto Legislativo

ET Estatuto de los trabajadores

LFE Ley de Fomento del Empleo

OIT Organización Internacional del Trabajo

RD Real Decreto

Res. Leg. Resolución Legislativa

TUO Texto Único Ordenado

\section{FUENTES}

\section{Legislación Internacional:}

Declaración Universal de los Derechos Humanos. (Aprobada por el Perú mediante Res. Leg. No 13282 del 15/12/59).

Convenio $N^{\circ} 52$ de la OIT (Aprobado por el Perú mediante Res. Leg. $N^{\circ} 13284$ del 15/12/59).

Constitución de la Organización Internacional del Trabajo y Reglamento de la Conferencia Internacional del Trabajo, Ginebra, Oficina Internacional del Trabajo, 1982.

Convención de Viena sobre el derecho de los tratados (Hecho en Viena el $23 / 5 / 69)$.

\section{Legislación Nacional}

Constitución Política del Perú de 1993.

Constitución Política del Perú en 1979.

Legislación General del Trabajo, Trujillo, Normas Legales, 1997.

$N^{\circ}$ 26435: Ley del Tribunal Constitucional (expedido el 10/01/95). 
Ley $N^{\circ}$ 24968: Ley Procesal de la Acción Popular (dictada el 20/12/ 88).

D.S. No04-93-TR: Reglamento de la Ley de Fomento del Empleo (publicada el 26/4/93)

\section{Legislación Española}

Sampere Navarro, A. y Galiana Moreno, J. (ed.), Legislación laboral y de la seguridad social, Pamplona, Aranzadi, 1996.

\section{Bibliografía}

AA.VV.

1994 "Casos Especiales de CTS: Trabajadores sin Jornada Mínima”, Asesoría Laboral, $\mathrm{N}^{\circ} 41$, mayo.

\section{AA.VV.}

1996 “Descansos”, Asesoría Laboral, N62, febrero.

\section{AA.VV.}

1993 "El trabajo y la Seguridad Social en las Constituciones Peruanas", Asesoría Laboral, $N^{\circ} 26$, febrero.

\section{AA.VV.}

1997 "Derecho al Descanso Vacacional", Informativo Caballero Bustamante, $\mathrm{N}^{\circ} 371$, marzo.

\section{AA.VV.}

1993 "Descanso Vacacional", Asesoría Laboral, № 32, agosto.
AA.VV.,
1996 "Suspensión del Contrato de Trabajo", Asesoría Laboral, $\mathrm{N}^{\circ} 68$, agosto. 


\section{AA.VV.}

1996 "Reglamento de la Ley de Fomento del Empleo: Rectificaciones Saludables", Informe Laboral, N¹24, abril.

\section{AA.VV.}

1993 "Vacaciones para los trabajadores destacados", Análisis Laboral, Vol. XVII - 151, mayo.

Alonso Garcta, M.

1967 Curso de Derecho del Trabajo, $2^{\circ}$ ed., Barcelona, Ariel.

Alonso Olea, M., y M. Casas Baamonde

1991 Derecho del Trabajo, $12^{\circ}$ ed., Madrid, Universidad Complutense1.

Alonso Olea, $M$.

"La Reforma del Mercado de Trabajo", Themis, N³4.

Alonso Olea, M.

Las Fuentes del Derecho. En especial del Derecho del Trabajo según la Constitución, $2^{\circ}$ ed., Madrid, .

BARbero Marcos, J.

1993 Normas Internacionales del Trabajo de la OIT, Valladolid, Lex $\mathrm{N}^{\circ} 1993$.

BOISSONNAT, J.

1996 "Lucha contra el desempleo y reconstrucción del trabajo en Francia", Revista Internacional del Trabajo. $\mathrm{N}^{\circ} 1$.

Borrajo Da Cruz, E.,

1989 Introducción al Derecho del Trabajo, $6^{\circ}$ ed. Madrid, Tecnos S.A.

BRICEÑo RuIZ, A.

1985 Derecho Individual del Trabajo, México, Harla. 
Cabanellas, G.

1949 Tratado de Derecho Laboral, t.II., Buenos Aires, El Gráfico.

Cannesa Montejo, M.,

1994 "Los convenios de la OIT y la nueva Constitución peruana". Asesoría Laboral, $\mathrm{N}^{\circ} 37$, enero.

Carrillo Calle, $M$.

1994 "Los derechos laborales en la Constitución peruana de 1993 y su ubicación en el contexto constitucional hispanoamericano", Asesoría Laboral, No 37, enero4.

Carrillo Calle, $M$.

1994 "La OIT y el control Supranacional de la Legislación Internacional del Trabajo", Análisis Laboral, N²02, abril.

CORNEJO VARGAS, C.

1984 "Aciertos y Desaciertos de la Vigencia de Normas en el tiempo en la Constitución de 1993", Asesoría Laboral, $N^{\circ}$ 48, diciembre.

Dieguez, G.

1991 Colecciones del Derecho del Trabajo, $3^{\circ}$ ed., Madrid, Civitas,.

Chirinos Soto, E. y F. Chirinos Soto

1994 Constitución de 1993: Lectura y Comentario, Lima, Nerman.

Chirinos Soto, E.

1984 La Nueva Constitución al alcance de todos, $3^{\circ} \mathrm{ed}$., Lima, AFA Edit. Importadores.

De la Lama, M.,

1987 "Tratados en la Constitución", en F. Eguiguren Praeli, (Ed.), Constitución Política de 1979 y sus problemas de aplicación: 11 estudios interpretativos. Lima, Cultural Cuzco,. 
De los Heros, A.

1996 "La Reforma Laboral y sus efectos", Themis, № 33.

ERMIDA URIARTE, O.

1993 "Constitucionalización del Derecho Laboral". Asesoría Laboral, $\mathrm{N}^{\circ}$ febrero.

García de Enterría, E. y T. Fernández

1993 Curso de Derecho Administrativo, $6^{\circ}$ ed., v.I, Madrid, Civitas.

Garcia Ortega, J., J. Ramírez Martínez y T. Sala Franco

1994 Curso de Derecho del Trabajo, $3^{\circ}$ ed., Valencia, Tirant Lo Blanch.

Marshall, A., "Consecuencias económicas de los Regímenes de Protección de los trabajadores en América Latina", Revista Internacional del Trabajo, $\mathrm{N}^{\circ} 1$, enero.

Merino Senovilla,H.

1994 El trabajo a tiempo parcial, Valladolid, Lex Nova.

Montoya Melgar, A.

1992 Derecho del trabajo, $13^{\circ}$ ed., Madrid, Tecnos.

Neves Mujica, J.

1997 Introducción al Derecho del Trabajo, $1^{\circ}$ ed., Lima, Ara Editores.

Neves Mujica, J.

1994 "Los principios del Derecho del Trabajo, en la Constitución y en el Proyecto", Asesoría Laboral, $\mathrm{N}^{\circ} 37$, enero.

Neves Mujica, J.

1993 "Vigencia de las Normas Laborales en el tiempo", Asesoría Laboral, $\mathrm{N}^{\circ} 27$, marzo. 
Neves Mujica, J.

1994 "Impuestos de aplicación de normas laborales", Asesoría Laboral, N³8, febrero.

OIT

1984 Manual sobre procedimientos en materia de convenios y recomendaciones internacionales del trabajo, Ginebra, Oficina Internacional del Trabajo.

Ojeda Aviles, A.

1994 "El Contrato a tiempo parcial en España", Asesoría Laboral, $N^{\circ} 40$, abril.

Pasco Cosmórolis, $\mathrm{M}$.

1996 "Flexibilización y Desregulación", Themis, N 34.

Pastor Ridrovejo, J.

1992 Curso de Derecho Internacional Público y Organizaciones Internacionales, $4^{\mathrm{a}}$ ed., Madrid, Tecnos.

RONDÓN VÁSQUEZ, J.

1995 Derecho del trabajo individual, Lima, Edial.

RUPRECHT, A.

1981 "Vacaciones" en Enciclopedia Jurídica Omeba, v.XXVI, Buenos Aires, Bibliográfica Omeba, 1981.

SANGUineti URiarte, W.

1993 "Los Contratos a Modalidad de la Ley de Fomento del Empleo", Asesoría Laboral, No 26, febrero/1993.

Von Potobsky, G. Y H. Bartolomei de la Cruz

1990 La Organización Internacional del Trabajo, Buenos Aires, Astrea, 1990.

Zavala Costa, J.

1994 "Remuneraciones y Jornadas de Trabajo", Asesoría Laboral, $N^{\circ} 37$, enero/1994. 